\title{
Flexible Job Shop Scheduling using Software
}

\author{
Prathipati Nikhil, K.N.Phanindra, P.Venkata Chalapathi, Mohammed Ikram, B.Akhil
}

\begin{abstract}
This present paper speaks about Flexible Job Shop scheduling Problem using a software. Flexible Job shop scheduling is most typical and complex manufacturing environments in production planning issues. A case study was conducted on a manufacturing business set in Vijayawada. Information collected from the producing company to get the time taken by the conventional scheduling method and gathered data for 5 jobs requiring 8 machines that arrived during the analysis period. The Project additionally speaks about the study of varied programming strategies, learning of LEKIN programming package is a software tool has a flexibility to develop new heuristic models to produce effective schedules be applied practically. Input data, taken from the manufacturing company, converted to tables and routing sequences. The LEKIN programming package [3], develops the different schedules for given data with reference to priority rules, such as First Come First Serve (FCFS), Longest Processing Time (LPT), Shortest Processing Time (SPT), Earliest Due Date (EDD), Critical Ratio (CR) [6]. The schedules obtained from priority rules analysed through performance measures like Make Span, No of late jobs, Total Flow Time, Total Tardiness, Maximum Tardiness, Total Weighted Tardiness, Total Weighted Flow Time. Our goal is to come up with a optimized schedule with in the process of flexible job shop scheduling by using LEKIN scheduling software, using various priority rules as mentioned above and to minimize the make span i.e. the time length of the schedule, during which all the operations for all jobs is completed in an engineering company.
\end{abstract}

Keyword : Flexible job shop scheduling, dispatching rules, performance measures, simulation on software.

\section{INTRODUCTION}

\subsection{Introduction to scheduling:}

Scheduling is a method to arrange, control and optimize works in a manufacturing plant. It employees the work in plant for machinery resources and human resources [1]. Scheduling is very crucial in manufacturing industry. It effects on the productivity of a process. In manufacturing, the purpose of scheduling is to minimize the completion times of all machines and other costs, it also have significant impact on maintenance of inventory. Production scheduling aims to increase the potency of the operation and scale back prices. In some situations, scheduling will involves random sequence, like trail and error method during machine breakdowns [6]. In this case, the scheduling is called as Stochastic scheduling.

Revised Manuscript Received on February 05, 2020.

* Correspondence Author

Prathipati Nikhil*, B. Tech, KL deemed to be university in INDIA

K.N.Phanindra, B.Tech, Kluniversity, india

P. Venkata Chalapathi, Professor in KL deemed to be University, received B.Tech in Mechanical Engineering from Acharya Nagarjuna University

Mohammed Ikram, B. Tech in Mechanical engineering at KL deemed to be University.

B.Akhil, B.Tech, KL deemed to be University.

smoussa@cud.ac.ae

(C) The Authors. Published by Blue Eyes Intelligence Engineering and Sciences Publication (BEIESP). This is an open access article under the CC BY-NC-ND license (http://creativecommons.org/licenses/by-nc-nd/4.0/)
The present case study is mainly focus on the Flexible Job Shop Scheduling Problem [8], which specifies a complex problem in Scheduling where the tasks are assigned to each machine with respect to time. Allocation of job on each machine is on the basis of various practical scenarios and priority rules.

\subsection{Literature review:}

\subsubsection{Scheduling \& Types:}

Scheduling is done on the basis of availability of machines and type of operations performed with sequence on the preferred jobs. Different schedules can be developed by same data with different priority rules. Optimized schedule is identified by comparison of performance measures [2]. Scheduling is categorized into

a. Single machine scheduling

b. Parallel machine scheduling

c. Flow Shop Scheduling

d. Flexible flow shop scheduling

e. Job Shop Scheduling

f. Flexible job shop scheduling

\section{a) Single machine scheduling :}

Single machine scheduling is a process to assign a group of tasks in a sequence to a single machine. The make spam and completion time will be same for all the priority rules. The tardiness changes with priority rules helps to improve performance of manufacturing plant.

b) Parallel machine scheduling :

More than one machine can perform same operation in one or multiple stages for processing jobs. The jobs processed in stages of manufacturing. All the performance parameters vary for all priority rules.

\section{Flow shop scheduling :}

$\mathrm{N}$ no of machines, each can perform single variety of operations and $\mathrm{M}$ no of jobs pass through all $\mathrm{N}$ machines for processing. The performance parameters are different for different priority rules.

\section{c) Flexible Flow Shop Scheduling :}

Combination of both parallel machine scheduling and flow shop scheduling, where the available of multiple machines for performing the same operation in some stages of process. Jobs should undergo all the stages of a flow line.

\section{Job shop scheduling :}

It is a complex scheduling. High possibility for idle time in machines and waiting time of jobs. Each job has its own routing sequence for performing the operations .No duplication of machines in the schedule. 


\section{d) Flexible Job shop Production :}

Duplication of machines in the system. Each job has unique routing sequence. It is mathematically called as NP problems, very complex to solve. This production is preferred in conditions having multiple jobs and limited volume of production [5].

\subsubsection{Dispatching rules :}

The set of jobs arranged in a sequence, with the consideration of all input parameters such as processing time, due dates, weight. These sequence influence on performance measures [6]. There are also called as priority rules. These scheduling rules results the optimum sequence [6].

\subsubsection{First come - First Serve Rule (FCFS) :}

It is a simple rule. The job arrives first will occupies first position in the sequence. Sequence has been designed on the arrival of the job [6].

The processing performed according to the sequence. In some conditions, this priority rule show optimized schedule in the consideration of all performance parameters.

\subsubsection{Shortest Processing Time (SPT) :}

This priority rule based on the processing time. The job places first having less processing time [6]. The sequence of jobs is based on the ascending order of the processing time. It shows optimize schedule in most cases. For all scenarios it shows the good schedule.

\subsubsection{Earliest Due date (EDD) :}

Scheduling of operations based on due date. The nearer due date occupies the first place of the sequence. This rule is used to reduce the tardiness in schedule. Less tardiness improves various performance parameters in the schedule.

\subsubsection{Critical Ratio (CR) :}

Critical ratio rule is based on formulae, difference between due date and processing time by remaining shop time. The result having less value be first in sequence. The total scheduling is made in consideration of the ratio from different jobs.

\subsubsection{Longest Processing Time (LPT) :}

Reverse of the shortest processing. Job places in first of sequence having highest processing time. Sequence is made in descending order of processing time. High possibility of make span in the schedule. In rare cases, it provides potential solution.

\subsubsection{Performance measures:}

\subsubsection{Make Span:}

Determines total length of schedule. Amount of time taken to complete scheduled operations on all jobs. It is the completion time of the last job in the schedule.

$$
\mathrm{MS}=\max \text { of }(\mathrm{C} \mathrm{i})
$$

\subsubsection{Tardiness :}

It shows the positive difference between completion time and due date for each job. Tardiness shows the delay in job than the expected due date. Negative value can consider as zero.

$$
\mathrm{T} \mathrm{i}=\text { only consider positive diff }\{\mathrm{C} \mathrm{i}-\mathrm{D} \mathrm{i}\}
$$

\subsubsection{Late jobs :}

It is the completion of job $\mathrm{J}$ differs from the due date. It changes for every job in the schedule. Negative numerical indicates the job has done early. Positive numerical indicates late in job. Zero indicates job complete on time.

$$
\mathrm{Li}=\mathrm{Ci}-\mathrm{D} \mathrm{i}
$$

no of late jobs= no of negative numerical jobs

\subsubsection{Flow Time :}

It is sum of all completion times for all jobs in the schedule. it shows the waiting time in jobs.

\subsubsection{Total tardiness:}

$$
\mathrm{F}=\sum(\mathrm{C} i) \text {. }
$$

Sum of tardiness in all jobs in the schedule.

$$
\text { Total tardiness }=\sum(\mathrm{T} \mathrm{i})
$$

\subsubsection{Total weighted tardiness:}

All tardiness is added with consideration of weight in each job.

$$
\begin{aligned}
& \text { Total weighted tardiness }=\sum(\mathrm{W} i . \mathrm{T} \text { i }) \\
& \mathrm{W} \mathrm{i}=\text { weight of a job }
\end{aligned}
$$

\subsubsection{Total weighted flow time:}

Sum of product with completion time and weight for all jobs Total weighted flow time $=\sum$ (W i. C i)

$$
\mathrm{C} \mathrm{i}=\text { completion time of a job. }
$$

\section{ANALYTICAL DATA}

\subsection{Profile of the company :}

Kristna Engineering works Pvt Ltd, Vijayawada is a reputed organization involved in the manufacturing of machinery components. Since 1962, Kristna Engineering has been playing a crucial role in producing of sugar industry machine components and ensuring them by providing premium quality checks, updating to latest technology for the improvement of processes. This company fabricates various machine components for cement, thermal, mining and other industries.

Kristna Engineering works is the manufacturers of specified parts in cast Iron, mild steel and other grades of castings required for needs of commercial Industries. They also produce the spare parts and equipment required for sugar cane, cement, thermal, mining and other industries. The company is good competitor in the production of heavy machinery parts in India, to meet global market standards

\subsection{Details of Problem: Machines Available:}

\begin{tabular}{|c|c|c|}
\hline $\begin{array}{c}\text { Machine } \\
\text { No }\end{array}$ & Machine Name & $\begin{array}{c}\text { No Of } \\
\text { Machines }\end{array}$ \\
\hline W001 & Planar Machine & 1 \\
\hline W002 & $\begin{array}{c}\text { Horizontal Boring } \\
\text { Machine }\end{array}$ & 1 \\
\hline W003 & Groove Machine & 1 \\
\hline W004 & Drill Machine & 2 \\
\hline W005 & Lathe Machine & 2 \\
\hline W006 & Milling Machine & 1 \\
\hline W007 & Slotter Machine & 1 \\
\hline
\end{tabular}




\begin{tabular}{|l|l|l|}
\hline W008 & Turning Machine & 1 \\
\hline
\end{tabular}

Parts to be Machined :

\begin{tabular}{|c|c|c|c|}
\hline Part No & Part Name & Weight & Due Date \\
\hline J001 & $\begin{array}{c}\text { Scrapper } \\
\text { Plate }\end{array}$ & 3 & 60 \\
\hline J002 & Cutter Hub & 4 & 48 \\
\hline J003 & Pinion & 2 & 56 \\
\hline J004 & $\begin{array}{c}\text { Bearing } \\
\text { Housing }\end{array}$ & 5 & 58 \\
\hline J005 & Spocket & 1 & 38 \\
\hline
\end{tabular}

\subsection{Problem Definition :}

In Flexible Job Shop Scheduling Problem, There is a set of $\mathrm{n}$ jobs $\mathrm{J} 00, \ldots . ., \mathrm{J} 00 \mathrm{n}$ and passes through m machines W001, ..., W00n available in the manufacturing plant. Each job Ji has its own sequence of operations. Possibility of duplicate machines, more than one machine can perform same operation.

\section{Routing:}

\begin{tabular}{|c|c|c|c|c|}
\hline Job & $\mathbf{1}$ & $\mathbf{2}$ & $\mathbf{3}$ & $\mathbf{4}$ \\
\hline $\mathbf{0 1}$ & W001 & W002 & W003 & W004 \\
\hline $\mathbf{0 2}$ & W005 & W006 & W004 & \\
\hline $\mathbf{0 3}$ & W005 & W007 & & \\
\hline $\mathbf{0 4}$ & W005 & W006 & W004 & \\
\hline $\mathbf{0 5}$ & W008 & W007 & & \\
\hline
\end{tabular}

\section{Processing Time(hrs):}

\begin{tabular}{|c|c|c|c|c|}
\hline Job & $\mathbf{1}$ & $\mathbf{2}$ & $\mathbf{3}$ & $\mathbf{4}$ \\
\hline $\mathbf{0 1}$ & 24 & 4 & 24 & 6 \\
\hline $\mathbf{0 2}$ & 8 & 8 & 2 & \\
\hline $\mathbf{0 3}$ & 24 & 24 & & \\
\hline $\mathbf{0 4}$ & 16 & 8 & 4 & \\
\hline $\mathbf{0 5}$ & 24 & 12 & & \\
\hline
\end{tabular}

\subsection{Software Used:}

LEKIN is a system used to schedule machines. This Schedule system was[9] invented by Stern School of Business, NYU. Professor Michael L. Pinedo, Professor Xiuli Chao and Professor Joseph Leuntedg directed this project. Columbia University students were designed and coded major elements in this software[3]. National Science Foundation partially supported for the development of this software[7]. LEKIN is a software tool used to schedule jobs on machines and to observe performance measures. Besides that, the system has flexibility for algorithm development. Flexible job shop priority rules used in LEKIN include EDD, MS, LPT, SPT, FCFS, and CR rule. Performance measures are make span, flow time, total weighted flow time, total tardiness, maximum tardiness, late jobs, total weighted tardiness, machine utilization [4].

Machine scheduling Present in LEKIN:

1. Single machine scheduling

\section{Parallel machines scheduling \\ 3. Flow shop scheduling \\ 4. Job shop scheduling \\ 5. Flexible Flow shop scheduling \\ 6. Flexible Job shop scheduling}

\section{SCHEDULING}

\subsection{Scheduling in LEKIN software :}

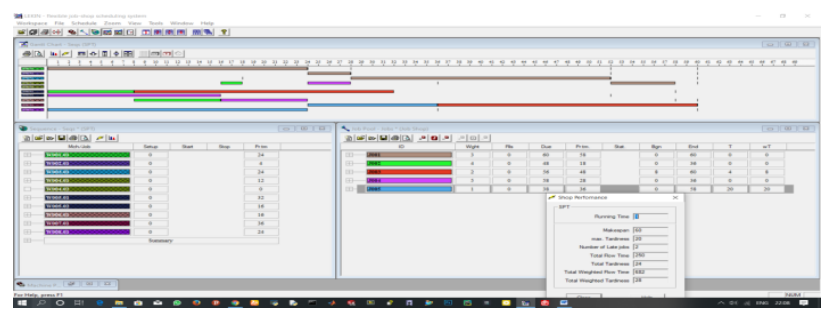

Shortest Processing Time(SPT)

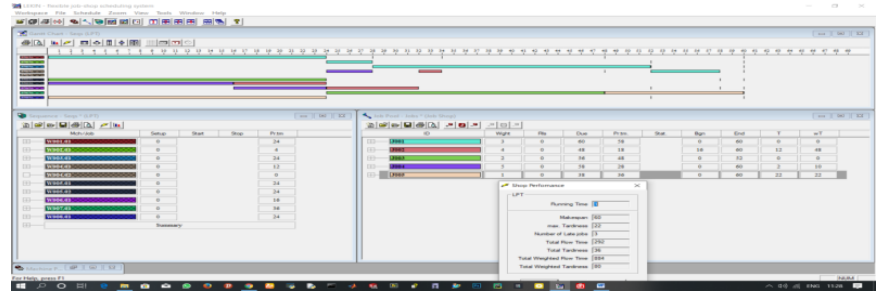

LongestProcessingTime(LPT)

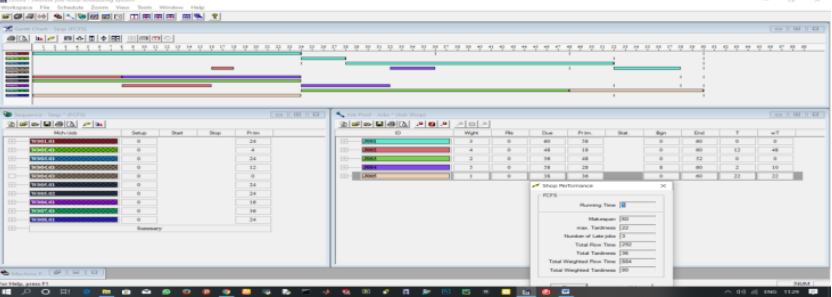

First come First serve(FCFS)

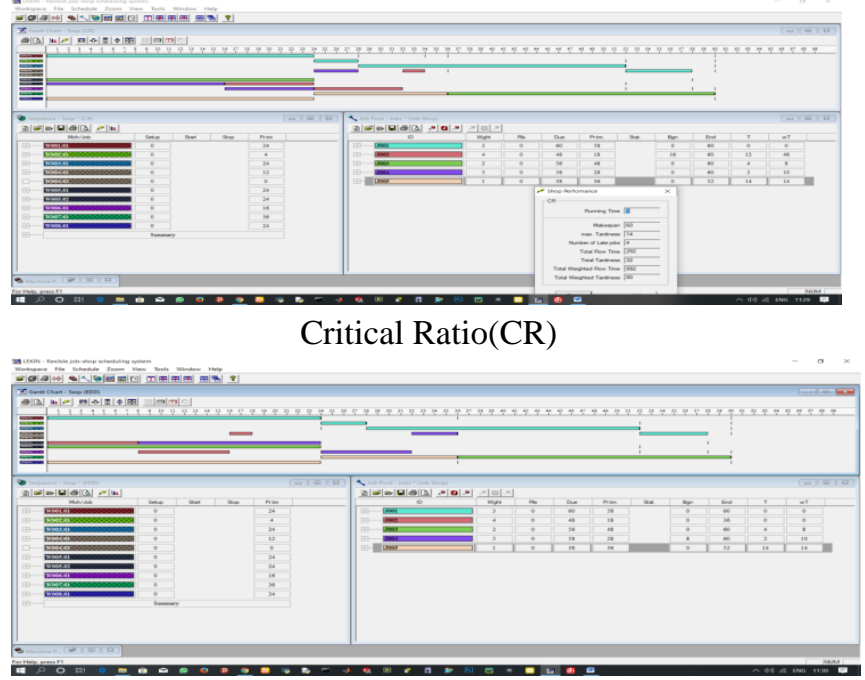

Earliest Due Date(EDD)

\section{RESULTS \& DISCUSSION}

Results obtained from LEKIN Software are performance measures. The performance measures are used to improve the efficiency of scheduling by minimizing the idle time in machines and waiting time of jobs. Analysis was performed under five priority rules with input taken from the company. The output as follows .

Published By:

Blue Eyes Intelligence Engineering \& Sciences Publication 


\subsection{Performance Analysis:}

\begin{tabular}{|c|c|c|c|c|c|c|c|}
\hline $\begin{array}{l}\text { Dispat } \\
\text { ching Rules }\end{array}$ & $\begin{array}{l}\text { Jakie } \\
\text { Span }\end{array}$ & $\begin{array}{l}\text { Marimm } \\
\text { Tardines }\end{array}$ & $\begin{array}{l}\text { Late } \\
\text { jobs }\end{array}$ & $\begin{array}{l}\text { Total } \\
\text { Flor time }\end{array}$ & Total Tardines & $\begin{array}{c}\text { Total } \\
\text { Weightd Flow } \\
\text { Time }\end{array}$ & $\begin{array}{l}\text { Total Weightited } \\
\text { Tardiness }\end{array}$ \\
\hline SPI & 60 & 20 & ? & 150 & It & 682 & 28 \\
\hline LPI & 60 & UI & 3 & 292 & 36 & 884 & 80 \\
\hline FSFC & 60 & U1 & 3 & 262 & 36 & 884 & 80 \\
\hline$C \mathbb{R}$ & 60 & It & $t$ & 292 & 32 & $89 \%$ & 80 \\
\hline EDD & 60 & It & 3 & 293 & 20 & 796 & 32 \\
\hline
\end{tabular}

\section{Chart Of Comparision}

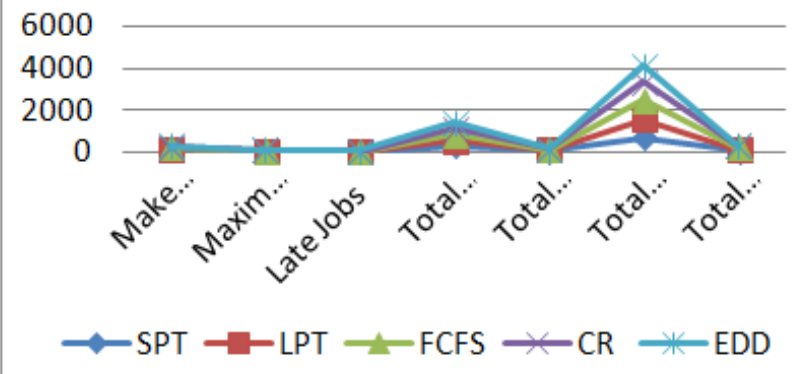

\subsection{Inference:}

a. Make Span is same for all the Dispatching rules.

b. Maximum Tardiness is low for Earliest due date \& Critical Ratio.

c. Total Flow time is low for Shortest Processing Time.

d. No of late jobs will be low for Shortest Processing Time.

e. Total Tardiness is less for Earliest Due Date and high for Longest Processing Time.

f. Total Weighted Time \& Tardiness is low for Shortest Processing Time.

\section{SUMMARY}

From above case study, flexible job shop scheduling problem for five jobs were scheduled by using LEKIN software. Shortest Processing Time (SPT), Longest Processing Time (LPT), First Come First Serve (FCFS), Critical ratio (CR), Earliest Due Date (EDD) are the five priority rules used for comparison of seven performance measures. Performance measures are make span, Flow time, Total Weighted Flow Time, Total Tardiness, Maximum Tardiness, Late Jobs, Total Weighted Tardiness. Software develops Schedules for given data taken from the company. For different practical scenarios different performance measures are taken into consideration. In most cases Shortest processing time shows optimal scheduling values than other priority rules. In this case study, using LEKIN scheduling software shortest processing (SPT) has shown in better performance in no of Late jobs, Total weighted Flow Time, Total Flow Time, Total Weighted tardiness is achieved.

\section{REFERENCES}

1. A Job-Shop Scheduling Model of Software Development Planning for Constraint-based Local Search (International Journal of Software Engineering and Its Applications Vol. 4., No. 4.., October 2010)

2. Optimization of job shop schedules using LEKIN® scheduling system.( International Journal of Engineering and Technical Research (IJETR) ISSN: 2321-0869 (O) 2454-4698 (P), Volume-4, Issue-2, February 2016)

3. A Simulation Modeling Approach for Job Shop Scheduling Problems: Case of Metal Industry ( International Journal of Science and Research (IJSR) ISSN: 2319-7064 Index Copernicus Value (2016): 79.57 Impact Factor (2017): 7.296)

4. A Job-Shop Scheduling Model of Software Development Planning for Constraint-based Local Search (International Journal of Software Engineering and Its Applications Vol. 4., No. 4.., October 2010)

5. []Holthaus O. and Rajendran C., 1990. "A comparative of study of dispatching rules in Dynamic flow shops and job shops". European journal of operational research.

6. Analyzing job shop scheduling problem by using dispatching rules (HOD, Department of Mechanical Engineering, Bule Hora University, Ethiopia 2Lecturer, Department of Mechanical Engineering, Bule Hora University, Ethiopia)

7. E. W. S. H. Prof. Dr. Gamal M. Nawara, "Solving the Job-Shop Scheduling Problem by Arena," vol. 2 , no. 2, 2013.

8. J. K. \&. B. Eshetie, "JobShop Scheduling Problem for Machine Shop with Shifting," vol. 15, no. 1, 2015..

9. A Simulation Modeling Approach for Job Shop Scheduling Problems: Case of Metal Industry (Dire Dawa Institute of Technology, School of Mechanical and Industrial Engineering, Dire Dawa University, Dire Dawa, Ethiopia)

\section{AUTHORS PROFILE}

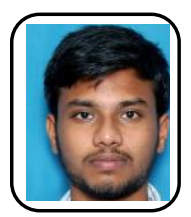

Prathipati Nikhil, studying final year B. Tech in KL deemed to be university in INDIA. I completed my intermediate in Sri Chaitanya junior college Guntur and I completed my $10^{\text {th }}$ class in Vignan high school Guntur. As part of my B. Tech project, we have done research on flexible job shop scheduling.

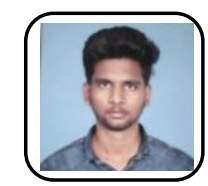

K. N. Phanindra, currently studying B.Tech in kluniversity in india. I completed $10^{\text {th }}$ in sri prakash vidya nikethan,,rajamundry and completed my intermediate in narayana junior college rajamundry.

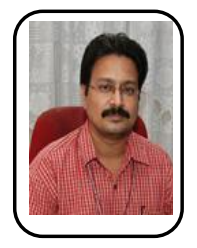

Dr.P.Venkata Chalapati, professor in KL deemed to be University, received B.Tech in Mechanical Engineering from Acharya Nagarjuna University; M.Tech in Industrial Engineering from R.E.C Calicut; and Ph.D from Osmania University. I have 4 years industrial experience and 19 years teaching experience. Life member of Indian Society for Technical Education and International Association of Engineers.

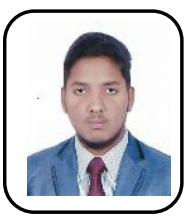

Mohammed Ikram, studying the final year of B. Tech in Mechanical engineering at KL deemed to be University. I completed my intermediate in Vijayawada and $10^{\text {th }}$ class in International Indian School Dammam,KSA. As a part of my B. Tech degree, we have done Research on Flexible job shop scheduling .

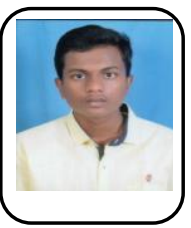

B.Akhil, studying final year B.Tech in KL deemed to be University, I studied $10^{\text {th }}$ in viswabharathi school in Gudivada and intermediate in Sri chaitanya junior college. I worked as Team Manager, Driver and Transmission stream member Vehicle fabrication in M Baja and Quad Bike Design Challenge(QBDC). 